\title{
Spatiotemporal heterogeneity of malnutrition indicators in children under 5 years of age in Bangladesh, 1999-2011
}

\author{
Md Tanvir Hasan ${ }^{1,2, *}$, Abdullah A Mamun ${ }^{3}$, Gail M Williams ${ }^{2}$ and \\ Ricardo J Soares Magalhães ${ }^{4,5}$ \\ 'BRAC James P Grant School of Public Health, BRAC University, 68 Shaheed Tajuddin Ahmed Sarani, Level 6, \\ icddrb Building, Mohakhali, Dhaka-1212, Bangladesh: ${ }^{2}$ School of Public Health, The University of Queensland, \\ Herston, QLD, Australia: ${ }^{3}$ Institute for Social Science Research, The University of Queensland, St Lucia, QLD, Australia: \\ ${ }^{4} \cup Q$ Spatial Epidemiology Laboratory, School of Veterinary Science, The University of Queensland, Gatton, QLD, \\ Australia: ${ }^{5}$ Children's Health Research Centre, The University of Queensland, South Brisbane, QLD, Australia
}

Submitted 21 July 2016: Final revision received 1 October 2017: Accepted 19 0ctober 2017: First published online 30 January 2018

\begin{abstract}
Objective: To examine changes in the spatial clustering of malnutrition in children under 5 years of age (under-5s) for the period 1999 to 2011 in Bangladesh.

Design: We used data from four nationally representative Demographic and Health Surveys (DHS) conducted in 1999-2000, 2004, 2007 and 2011 in Bangladesh involving a total of 24211 under-5s located in 1661 primary sampling units (PSU; geographical unit of analysis) throughout Bangladesh. The prevalence of stunting (height/length-for-age $Z$-score $<-2$ ), underweight (weight-for-age $Z$-score $<-2$ ) and wasting (weight-for-height/length $Z$-score $<-2$ ) at each PSU site and for each survey year were estimated based on the WHO child growth standard. The extent of spatial clustering was quantified using semivariograms.

Setting: Whole of Bangladesh.

Subjects: Children under 5 years of age.

Results: Our results demonstrate that in 1999-2000 most PSU throughout Bangladesh experienced stunting, underweight and wasting prevalence which exceeded the WHO thresholds. By 2011, this situation improved, although in two of the six divisions (Barisal and Sylhet) PSU still exhibited higher levels of malnutrition compared with other divisions of the country. The pattern of spatial clustering for stunting, underweight and wasting also changed between 1999 and 2011 both at national and sub-national (division) levels.

Conclusions: We identified divisions where malnutrition indicators (stunting, underweight and wasting) remain highly clustered and other divisions where they are more widely spread in Bangladesh. This has important implications on how interventions for malnutrition need to be delivered (geographically targeted interventions $v$. random interventions) within each division of the country.
\end{abstract}

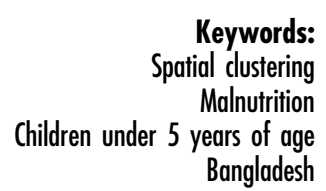

Malnutrition in children under 5 years of age (under- 5 s) is an important cause of childhood morbidity and mortality in low- and middle-income countries ${ }^{(1,2)}$. Reduction of malnutrition may increase child survival and is of great importance for better human and economic development and social equity ${ }^{(3)}$. It is widely argued that interventions to alleviate malnutrition are an effective approach to achieve several sustainable development goals ${ }^{(4)}$.

The burden of malnutrition in under- $5 \mathrm{~s}$ can be geographically heterogeneous. The prevalence of malnutrition may vary between countries because of such factors as gross national product, per capita national income, per capita food availability, governmental social support, national immunization rate, quality of the country's health environment, total child population, female education, female literacy rate, women's status relative to men's and presence of democracy $^{(5-8)}$. Within a country prevalence of malnutrition may vary among communities because of different levels of socio-economic development, community water and sanitation infrastructure, availability and accessibility to health and education services, cultural practices regarding food, community employment and social participation, and the education level of the community ${ }^{(9,10)}$. Moreover, communities with a high prevalence of malnutrition are likely to be surrounded by others with similar levels, giving rise to spatial clustering of malnutrition ${ }^{(11)}$. 
Spatial cluster analysis is a method used to quantify geographical aggregation of disease and thus allows identification of priority areas that require interventions. Several nutritional studies have applied spatial cluster analysis to identify geographical areas with a high rate of overweight/obesity $^{(12,13)}$ and high rate of low birth weight ${ }^{(14)}$. However, the application of this method in identifying high-prevalence areas of childhood malnutrition has so far been limited. Moreover, those that examined geographical disparities in malnutrition endemicity draw different conclusions. For example, some reported low, or moderately low, spatial clustering of stunting and wasting at national and sub-national levels, and highlighted limited benefits of geographically targeted nutrition interventions ${ }^{(15,16)}$; whereas others reported spatial clustering at the district level and concluded that geographically targeted interventions could be implemented along with individual- or household-level interventions $^{(11)}$. The question as to whether spatial clustering of malnutrition exists at national and sub-national levels within a country and whether this has evolved over time in the face of continuing interventions remains poorly understood. Such an approach will generate important evidence for implementing interventions that are geographically targeted to areas that have historically been unable to reduce malnutrition prevalence.

Bangladesh is a country in South Asia with high prevalence of childhood malnutrition. Over the years, the Government of Bangladesh, non-governmental organizations and other development agencies have implemented several nutrition interventions such as the National Nutrition Services, nutrition surveillance and homestead food production, the Vulnerable Group Development Programme and others to tackle maternal and child malnutrition ${ }^{(17)}$. These initiatives helped Bangladesh reduce childhood malnutrition during the past decades. However, the pace of reduction was uneven across socio-economic groups and geographical divisions ${ }^{(18)}$ (a division is the first administrative tier in the People's Republic of Bangladesh). While some divisions such as Khulna and Rajshahi are doing well in reduction of malnutrition, others such as Sylhet division is doing worse. The geographical discrepancy in effectiveness of malnutrition interventions could be associated with the presence of spatial clustering of malnutrition and the way nutrition interventions are currently delivered in each division of the country. For instance, if in a division, the prevalence of malnutrition is high and also spatially clustered, this would mean that a targeted geographical deployment of interventions would provide maximum benefit compared with a random intervention. Previous research conducted in Bangladesh documented why interventions implemented under National Nutrition Services failed to provide maximum benefit to improve nutrition situation in the country ${ }^{(19)}$; however, researchers are yet to explore the best delivery approach (i.e. geographically targeted $v$. random) to tackle malnutrition at the national and sub-national (divisional) levels in Bangladesh.

In the present study we investigated whether malnutrition indicators (stunting, underweight and wasting) in Bangladesh were spatially clustered at national and subnational levels, and whether these patterns changed between 1999 and 2011. The findings of our study can help public health practitioners to better understand the geographical distribution of the prevalence of stunting, underweight and wasting at small spatial scales in Bangladesh and to increase the effectiveness of the delivery format (geographically targeted deployment of interventions $v$. random deployment of interventions) within each division of the country.

\section{Methods}

\section{Data sources}

We used data from four Demographic and Health Surveys (DHS) conducted in 1999-2000, 2004, 2007 and 2011 in Bangladesh involving 24211 under-5s. For analysis of spatial clustering for stunting, underweight and wasting at the national level, we used 341 primary sampling units (PSU) from the 1999-2000 survey, 359 PSU from the 2004 survey, 361 PSU from the 2007 survey and 600 PSU from the 2011 survey. The flowchart of the sample selection is provided in Fig. 1. Bangladesh has seven administrative divisions: Barisal, Chittagong, Dhaka, Khulna, Rajshahi, Rangpur and Sylhet ${ }^{(20)}$. Rangpur division was formed from

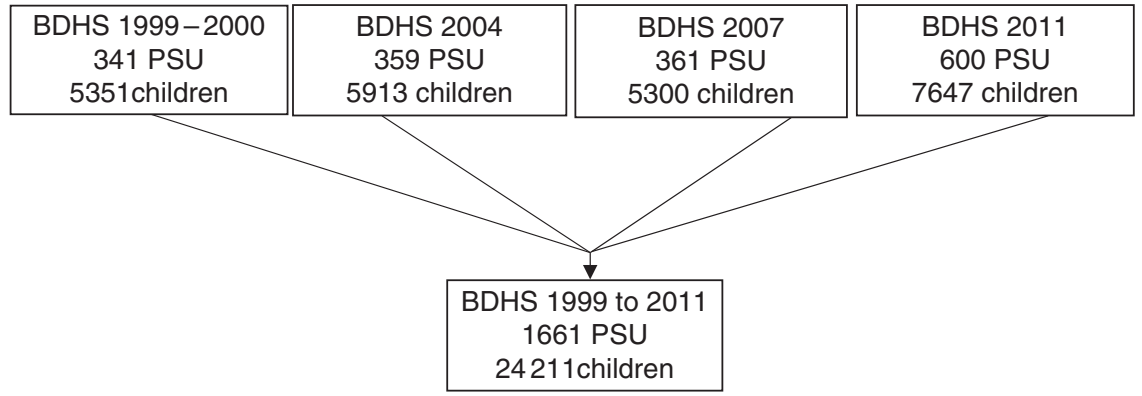

Fig. 1 Flowchart of the sample selection for the present study: primary sampling units (PSU) and children under 5 years of age from the Bangladesh Demographic and Health Surveys (BDHS) 1999-2000, 2004, 2007 and 2011 
the greater Rajshahi division in 2010. For analysis at the sub-national (division) level, we excluded information of eighty-five PSU from the 2011 survey for the Rangpur division because data were available for this division only for the most recent survey (2011). This exclusion allowed us to compare changes in spatial clustering of malnutrition indicators for the remaining six divisions for all survey years.

PSU (small geographical units that typically include 120-130 households) serve as the first sampling unit in the multistage stratified sampling used by the DHS to draw nationally representative sample of households in Bangladesh $^{(20,21)}$. Longitude and latitude for each of these PSU have been provided by DHS since the 1999-2000 survey in Bangladesh. More detailed information about the DHS global positioning system data collection is available elsewhere (http://www.dhsprogram.com/What-We-Do/ GPS-Data-Collection.cfm).

We assessed malnutrition status (stunted, underweight and wasted) of the sampled children based on their anthropometric indices data (height/length-for-age $Z$-score (HAZ), weight-for-age $Z$-score (WAZ) and weightfor-height/length $Z$-score $(\mathrm{WHZ}))^{(22)}$. The prevalence of stunting (HAZ $<-2)$, underweight (WAZ $<-2$ ) and wasting $(\mathrm{WHZ}<-2)$ at each PSU site and for each survey year were estimated based on the WHO child growth standards ${ }^{(23)}$. We applied sampling weights based on the unit of analysis (children) that accounts for disproportionate sampling and non-response of the DHS data.

\section{Statistical analyses}

We performed analyses in two steps: first, to visualize the spatiotemporal distribution of malnutrition across the country, we generated maps showing the observed prevalence of stunting, underweight and wasting at each PSU site in a geographical information system (ArcGIS version 10.2; ESRI). We categorized the observed prevalence based on the WHO classifications for assessing severity of malnutrition by prevalence ranges at the population level (for stunting: low (less than 20\%), medium (20-29\%), high (30-39\%), very high (at least $40 \%$ ); for underweight: low (less than 10\%), medium (10-19\%), high (20-29\%), very high (at least 30\%); for wasting: low (less than 5\%), medium (5-9\%), high (10-14\%), very high (at least $15 \%))^{(24)}$. Second, we quantified the extent of spatial clustering of stunting, underweight and wasting both at the national and sub-national (division) levels using semivariograms. A semivariogram is a plot used to examine spatial dependence between pairs of data points ${ }^{(25)}$ and is described by three important parameters (the range, sill and nugget) ${ }^{(25,26)}$. The nugget describes spatially uncorrelated (random) variation in the data, the partial sill (the sill minus the nugget) describes spatially autocorrelated variation in the data, and the range represents the distance at which spatial autocorrelation ceases ${ }^{(26)}$. The range is useful for measuring the average size of disease clusters, whereas the sill is useful for understanding geographical clustering ${ }^{(27)}$. We also calculated the proportion of variation due to spatial clustering (propensity of clustering) as follows: the sill divided by the sum of the sill and nugget. The geoR package of the statistical software $\mathrm{R}$ was used to examine spatial clustering ${ }^{(28)}$.

\section{Results}

\section{Overall spatiotemporal distribution of malnutrition indicators}

We included 1661 PSU with complete malnutrition data for a total of 24211 under-5s from Bangladesh. The spatial distribution of observed prevalence of stunting, underweight and wasting among under-5s for each survey year is presented in Fig. 2, 3 and 4, respectively. Results indicate very high prevalence of stunting (at least $40 \%$ ) and underweight (at least 30\%) in most PSU across the country in 1999 based on the WHO cut-offs. In contrast to stunting and underweight, the level of wasting did not decrease over time. In 2011, the prevalence of wasting was very high (at least 15\%) in most PSU throughout Bangladesh.

\section{Spatial clustering of malnutrition indicators at national level}

The semivariograms for prevalence of stunting, underweight and wasting at the national level are presented in Fig. 5. Spatial clustering in the prevalence of stunting was observed in all survey years except 2007. The average size of clusters was greater in 2004 (range $1.3 \mathrm{~km}$ ) compared with $1999-2000(0.2 \mathrm{~km})$ and $2011(0.7 \mathrm{~km})$. The propensity for clustering decreased from $96.7 \%$ in $1999-2000$ to $75.9 \%$ in 2007 but then increased to $89.9 \%$ in 2011. Spatial clustering in the prevalence of underweight was observed in 1999-2000 and in 2004. The size and propensity for clustering were larger in 1999-2000 (range $2.2 \mathrm{~km}$, propensity $87.2 \%)$ compared with $2004(0.5 \mathrm{~km}$, $78.8 \%$ ). Spatial clustering in the prevalence of wasting was observed in all survey years except 2011. The size of clusters decreased from $2.3 \mathrm{~km} 1999-2000$ to $0.3 \mathrm{~km}$ in 2007. The propensity for clustering also decreased from $95.4 \%$ in $1999-2000$ to $85.3 \%$ in 2011 .

\section{Spatial clustering of malnutrition indictors at sub-national (division) level}

Table 1 shows semivariogram parameter estimates for prevalence of stunting, underweight and wasting at the sub-national (division) level for each survey year. The corresponding semivariograms are provided in the online supplementary material. Spatial clustering in the prevalence of stunting was observed in all survey years in the capital (Dhaka division), south-west region (Khulna division), mid-western region (Rajshahi division) and north-east region (Sylhet division) of the country (Table 1). The size of clusters and the propensity of clustering in 

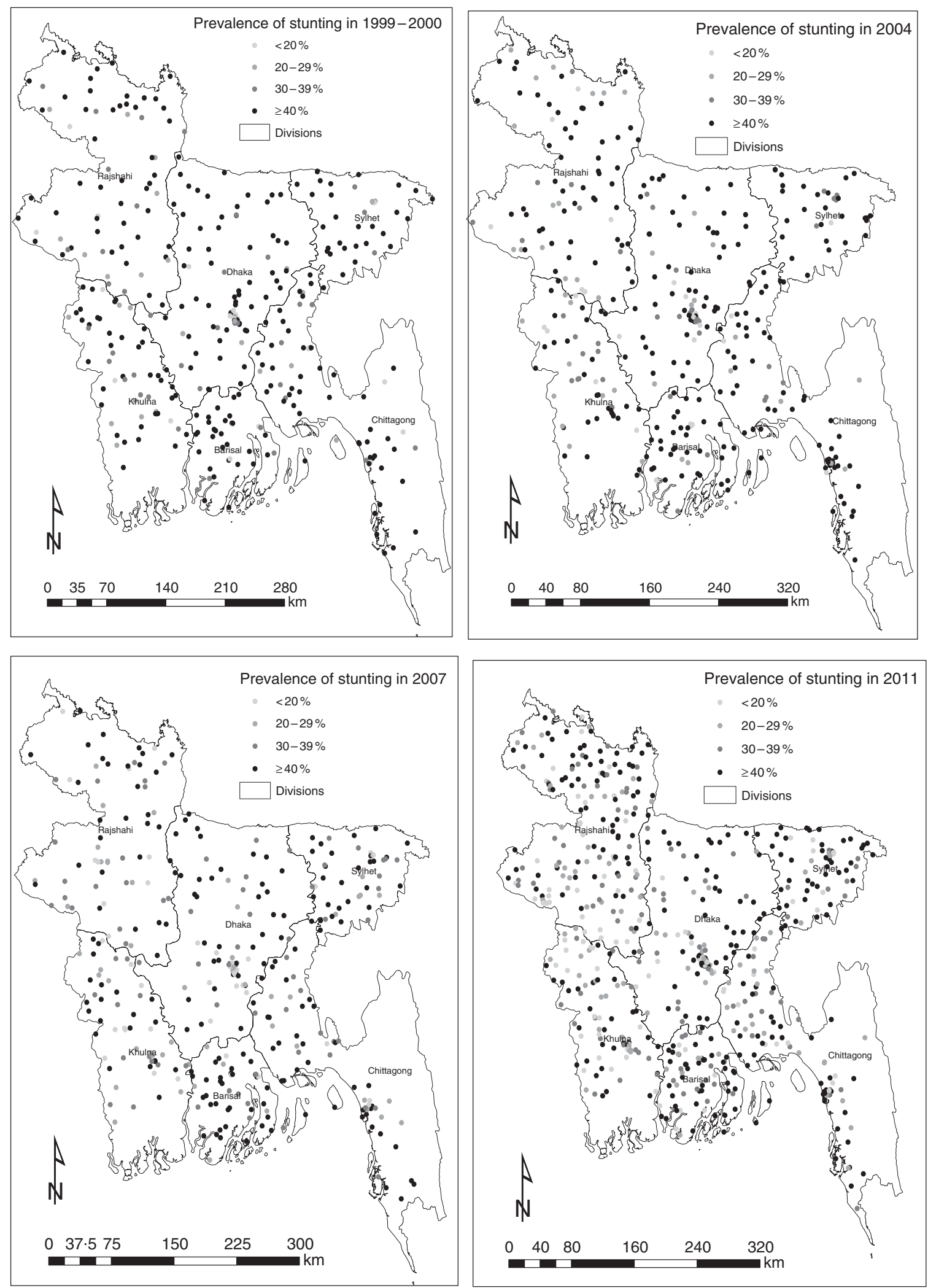

Fig. 2 Prevalence of stunting among 24211 children under 5 years of age at 1661 primary sampling units: Bangladesh Demographic and Health Surveys 1999-2000, 2004, 2007 and 2011 

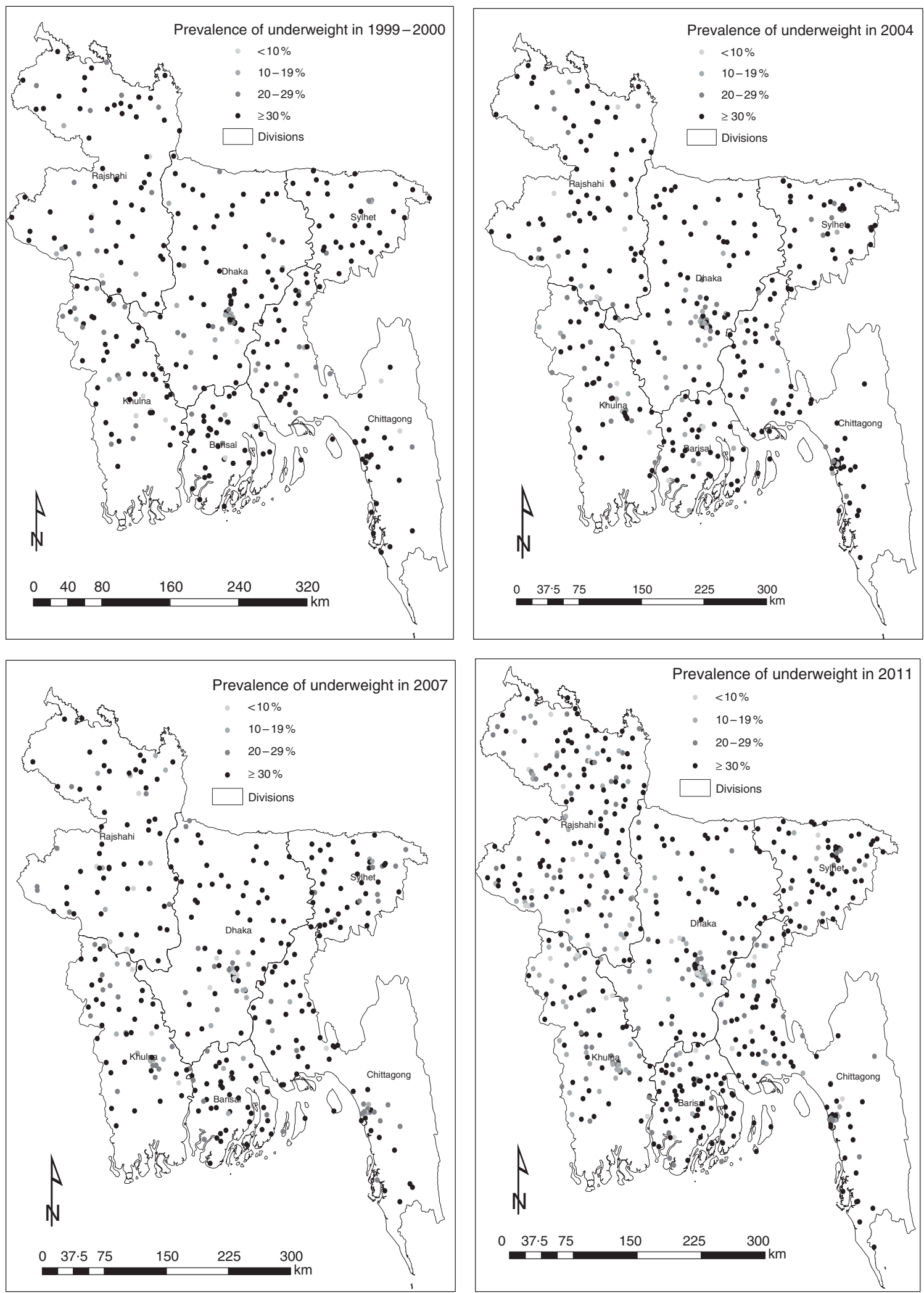

Fig. 3 Prevalence of underweight among 24211 children under 5 years of age at 1661 primary sampling units: Bangladesh Demographic and Health Surveys 1999-2000, 2004, 2007 and 2011 

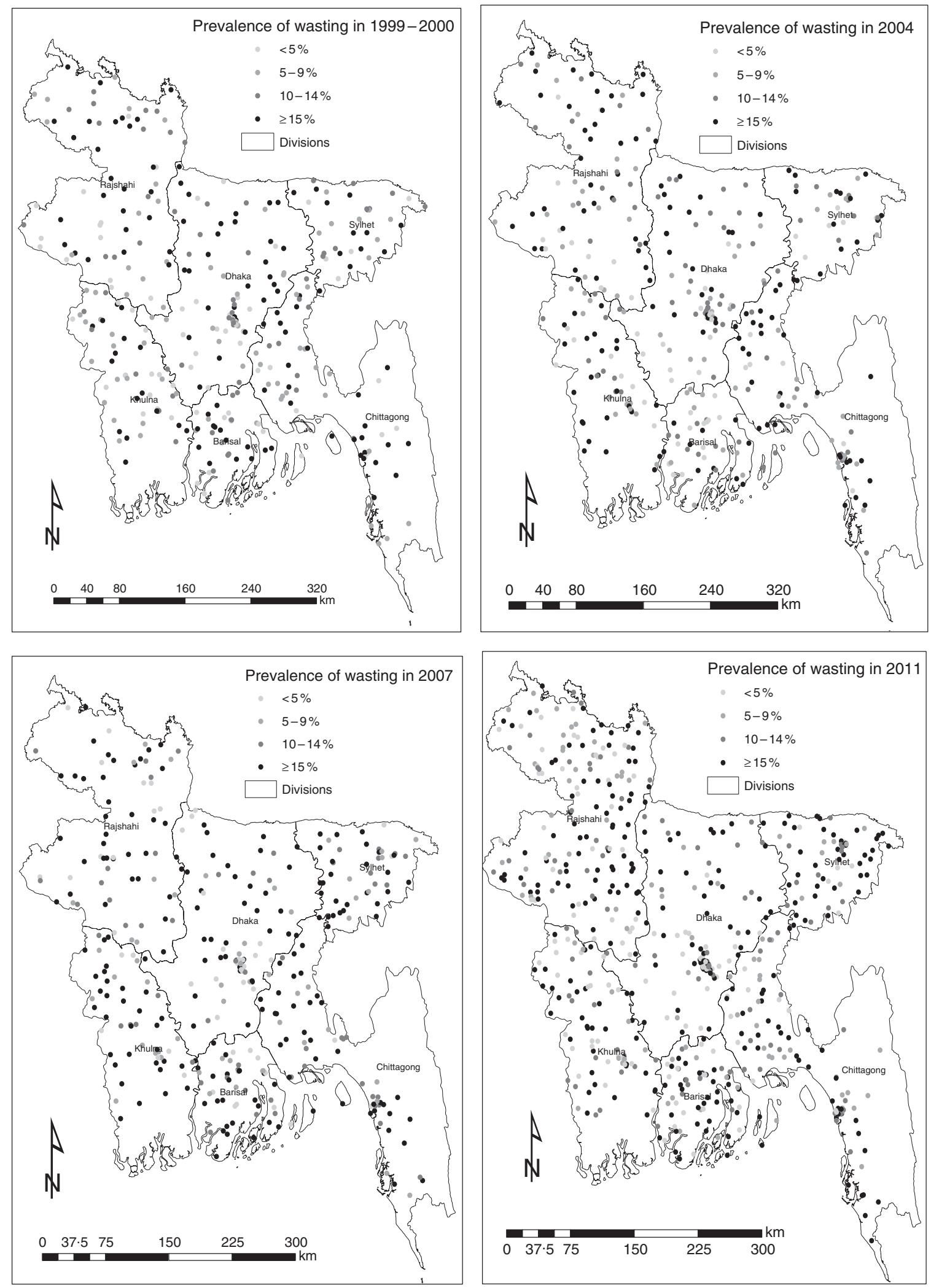

Fig. 4 Prevalence of wasting among 24211 children under 5 years of age at 1661 primary sampling units: Bangladesh Demographic and Health Surveys 1999-2000, 2004, 2007 and 2011 

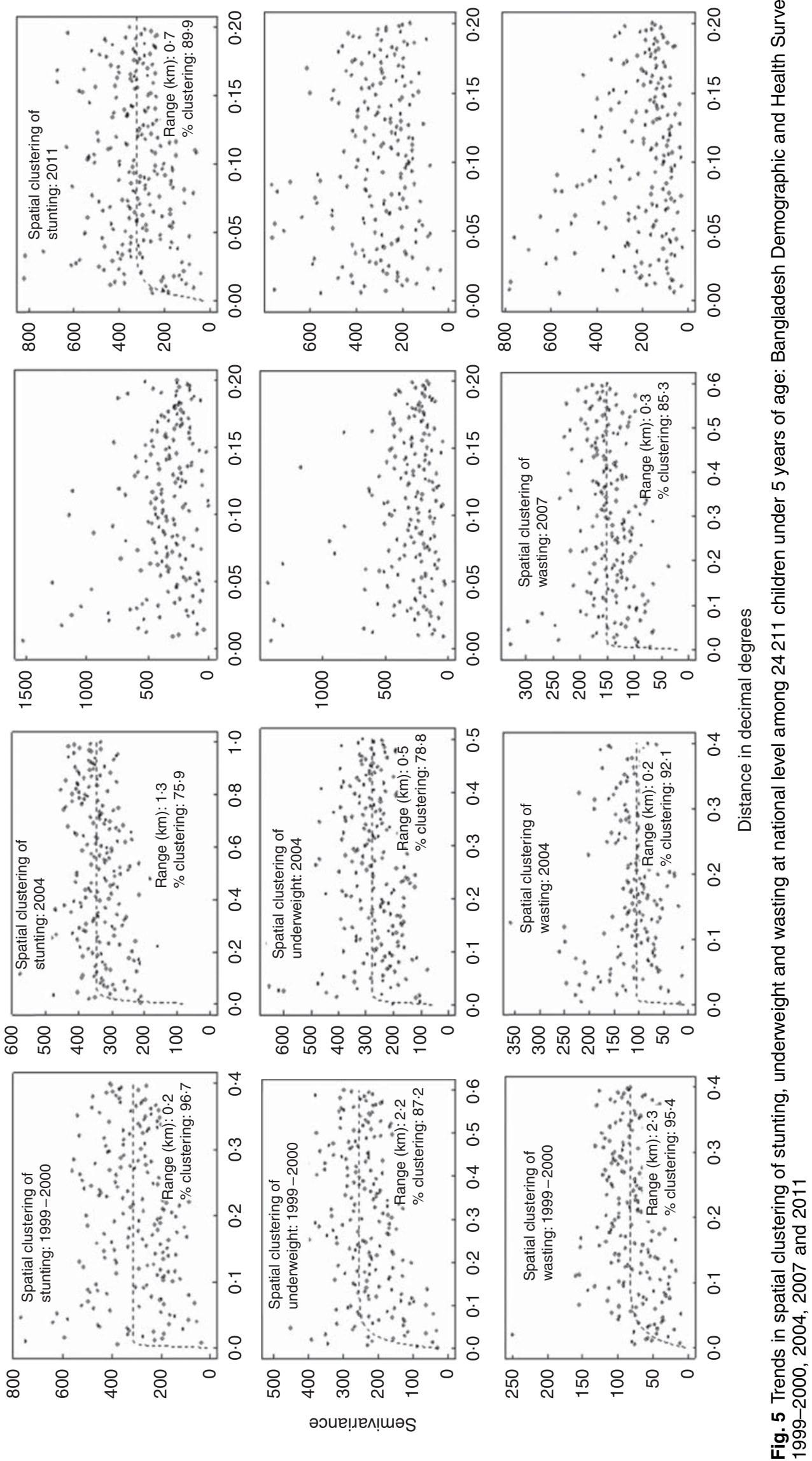


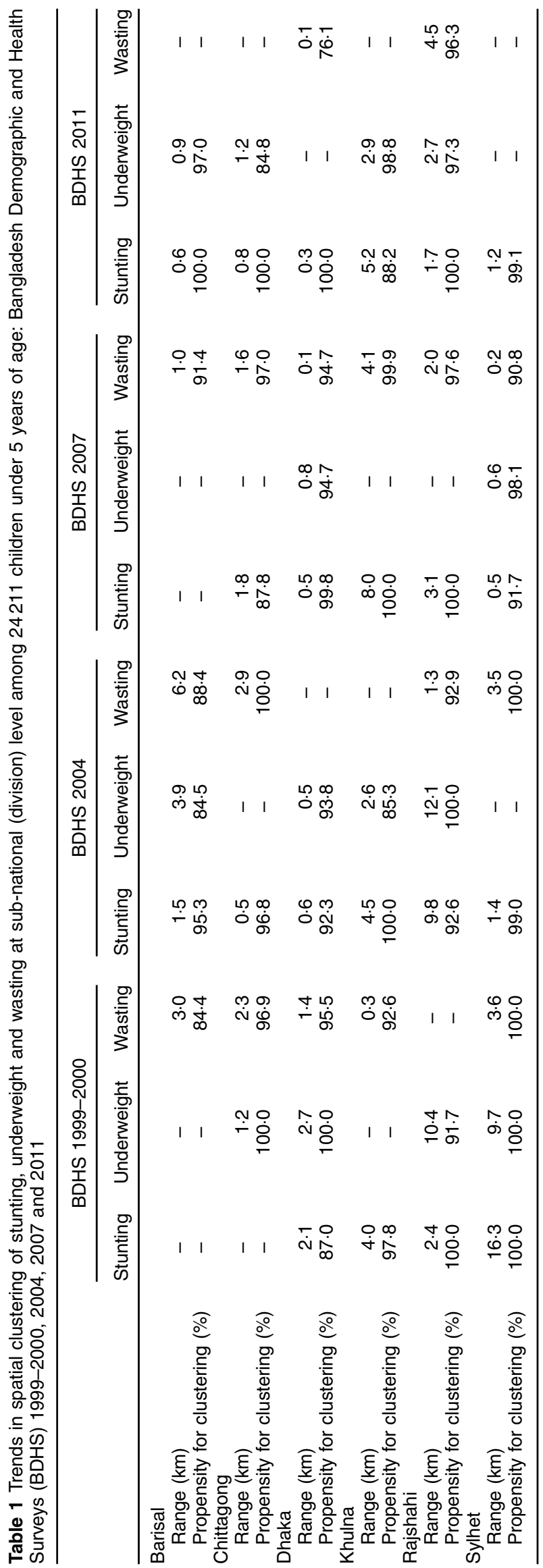

prevalence of stunting varied substantially across the regions. In Dhaka, the size of clusters decreased steadily from $2.1 \mathrm{~km}$ in $1999-2000$ to $0.3 \mathrm{~km}$ in 2011 . The propensity of clustering increased from $87 \%$ in $1999-2000$ to $100 \%$ in 2011. In Rajshahi and Sylhet, the size of clusters also decreased $(2.4$ and $16.3 \mathrm{~km}$, respectively, in 19992000 to 1.7 and $1.2 \mathrm{~km}$, respectively, in 2011 ). The propensity of clustering, however, remained unchanged.

Spatial clustering in the prevalence of underweight was observed in Chittagong, Dhaka, Rajshahi and Sylhet divisions in 1999-2000. This trend changed in 2011 when only two divisions (Chittagong and Rajshahi) exhibited spatial clustering. Between 1999 and 2011, the size of clusters remained unchanged in Chittagong division whereas it decreased in Rajshahi division. Clustering of prevalence of underweight was also observed in Barisal and Khulna divisions in 2004 and in 2011 with varying size of clusters and propensity for spatial clustering.

Spatial clustering in the prevalence of wasting was observed in all divisions except Rajshahi in 1999-2000. This trend continued until 2007 for three divisions - Barisal, Chittagong and Sylhet. The size of clusters decreased between 1999 and 2007 in the three divisions: Barisal, $3 \cdot 0$ to $1.0 \mathrm{~km}$; Chittagong, 2.3 to $1.6 \mathrm{~km}$; and Sylhet, 3.6 to $0.2 \mathrm{~km}$. Propensity of clustering increased in Barisal and Chittagong divisions from 1999 to 2007 whereas it decreased in Sylhet division. In 2011, clustering of wasting occurred only in Dhaka and Rajshahi divisions. The size of clusters was $0.1 \mathrm{~km}$ in Dhaka and $4.5 \mathrm{~km}$ in Rajshahi division.

\section{Discussion}

The present study is the first to report the spatial distribution and changes in spatial clustering in the prevalence of stunting, underweight and wasting in Bangladesh during the past 12 years (1999 to 2011). In 1999 most PSU throughout Bangladesh experienced malnutrition indicators which exceeded the WHO cut-offs. By 2011, severity of malnutrition generally decreased, although in two of the six divisions (Barisal and Sylhet) PSU still exhibited higher levels of malnutrition compared with other divisions of the country.

We found spatial clustering in the prevalence of stunting, underweight and wasting both at national level and at sub-national (division) level. At the national level, spatial clustering in the prevalence of stunting was found at the 1999-2000, 2004 and 2011 surveys; underweight at the 1999-2000 and 2004 surveys; and wasting at the 19992000, 2004 and 2007 surveys. The finding that the prevalence of stunting showed more clustering than the prevalence of underweight and wasting is in line with previous study findings ${ }^{(15)}$. Stunting, also known as chronic malnutrition, is closely associated with socioeconomic status and therefore exhibits more clustering $^{(16,29)}$. Several contextual factors such as poverty, poor 
sanitation and poor access to health-care services are associated with increased risk of stunting in children ${ }^{(30)}$. Although Bangladesh has witnessed steady economic progress over the last two decades, still $31 \%$ of the population lives below the poverty line and wide income disparities exist between urban and rural areas ${ }^{(31)}$. Only $34 \%$ of households have access to an improved toilet facility (not shared) ${ }^{(20)}$ and significant inequity remains in accessing health services, with people from the higher wealth quintiles enjoying the most benefits of both public and private health services ${ }^{(32)}$. Thus, it is expected that clustering for stunting might continue to exist until proper socio-economic development of the communities is achieved. Nevertheless, to tackle stunting on an urgent basis, the Government of Bangladesh needs to pay special focus to tackle poverty and economic inequality. In addition, it is important to adopt appropriate strategies to ensure that every household has access to sanitation and health-care services. Regarding tackling of wasting, which remained highly clustered until 2007 , we should note that it is indicator of acute malnutrition - a short-term deficiency in food supply or a recent episode of illness may cause wasting in children ${ }^{(33)}$. It is possible to reduce the burden of wasting by improving household income, food security, caring practices and controlling of infectious diseases $^{(33-35)}$.

At the divisional level, clustering in the prevalence of stunting was observed in all survey years in four of the six divisions - Dhaka, Khulna, Rajshahi and Sylhet. In 2011, the size of clusters varied substantially, with the average minimum size found in Dhaka division $(0.3 \mathrm{~km})$ and the maximum size in Khulna division $(5 \cdot 2 \mathrm{~km})$. These findings indicate that if a community with high prevalence of stunting is identified in Dhaka division, nutrition interventions can be implemented within $0.3 \mathrm{~km}$ radius from it; for Khulna division, this intervention needs to be implemented within $5 \cdot 2 \mathrm{~km}$ radius from the affected community. Unlike the four divisions (Dhaka, Khulna, Rajshahi and Sylhet), clustering in the prevalence of stunting was not observed in Barisal division (in 1999 and 2007) and in Chittagong division (in 1999), which may suggest that stunting was more evenly distributed in these two divisions compared with the four divisions (Dhaka, Khulna, Rajshahi and Sylhet) where stunting remained concentrated in certain pockets of areas. The socio-economic condition of the households in different divisions might be associated with these changing patterns. In addition, geographical location of the different divisions might have played a role. For example, Barisal division has the highest incidence of poverty and is considered the most vulnerable to natural hazards and frequent disasters compared with the other divisions, which makes its inhabitants especially children - vulnerable to food security, leading to chronic malnutrition ${ }^{(31,36)}$

We also observed spatial clustering in the prevalence of underweight in Chittagong and Rajshahi divisions in 1999 and 2011. The size of clusters decreased in Rajshahi division from $10.4 \mathrm{~km}$ in 1999 to $2.7 \mathrm{~km}$ in 2011, whereas it remained unchanged in Chittagong division. The reduction in cluster size in Rajshahi division might be associated with faster reduction in household poverty and improvements in vaccination coverage and maternal education $^{(20,37,38)}$. It is possible that in 1999 childhood underweight was highly prevalent among large population groups and in vast areas of Rajshahi division, thus generating a large geographical trend. However, over time, as a result of socio-economic improvements, high prevalence of underweight remained concentrated among fewer population groups and in small areas, thus generating a small geographical trend. This is also evident from the decreasing trend in the prevalence of underweight in Rajshahi division from $43 \cdot 3 \%$ in 1999 to $34 \cdot 1 \%$ in $2011^{(18)}$. In Chittagong division the size of clusters of underweight remained unchanged and small $(1.2 \mathrm{~km})$ over time, perhaps because of the high population density and presence of urban slums.

For wasting, we found spatial clustering in two divisions (Dhaka and Rajshahi) in 2011 compared with spatial clustering in all divisions in 2007 . The size of clusters in the two divisions also decreased between 2007 and 2011. This might indicate an improvement in the nutritional status of under-5s in 2011 compared with 2007, during which a major flood seriously affected more than half of Bangladesh. Dhaka, the capital of Bangladesh, is home to many slums which are characterized by a higher prevalence of malnutrition, anaemia and other poor health outcomes compared with other areas ${ }^{(17)}$. It is possible that geographical clusters observed in the present study include those slums. Similarly, Rajshahi division located in the north of Bangladesh is the second poorest division of Bangladesh $^{(38)}$ where many of its population experience a seasonal pattern of food shortages called monga ${ }^{(39)}$. It is possible that the geographical clusters include monga areas; this requires further investigation. Nevertheless, it should be noted that an absence of spatial clustering in the prevalence of wasting in Sylhet division in 2011 does not indicate that the problem is less severe, rather it may indicate that the problem is widespread and thus more evenly distributed across Sylhet division than in Dhaka and Rajshahi divisions.

The results of our study have important public health implications. Our divisional level semivariogram findings combined with divisional level malnutrition prevalence can provide a means to understand the type of interventions (geographically targeted interventions $v$. random interventions) required to tackle malnutrition in different divisions of the country. For instance, a division with a high prevalence of malnutrition indicators and a high tendency for spatial clustering means that programme planners should prioritize interventions to that division and the interventions will have to be geographically targeted because malnutrition in the division is very likely 
to be clustered; in this case random intervention delivery within the division would likely be ineffective. Thus, interventions targeting chronic malnutrition (stunting) can be implemented in high-prevalence communities across all divisions of Bangladesh with varying geographical scales (depending on the size of clusters). For childhood underweight, geographically targeted nutrition interventions can be implemented in high-prevalence communities of Barisal, Chittagong, Khulna and Rajshahi divisions. For childhood wasting, geographically targeted nutrition interventions can be implemented in high-prevalence communities of Dhaka and Rajshahi divisions. Previous studies have shown the influence of characteristics of communities, such as community hygiene and community socio-economic status, on the nutritional outcomes of children $^{(10,40-42)}$; some of these characteristics are spatially variable. A population-based study conducted in Bangladesh identified community levels of education, employment and social participation as important determinants of HAZ and WAZ among children ${ }^{(9)}$. Thus, spatial variation in social context is likely to be associated with local spatial variation in malnutrition outcomes and therefore it is necessary to promote health education and disease prevention at the community level ${ }^{(40)}$.

A potential limitation of our study is that while PSU were used as proxies for the communities ${ }^{(16,43)}$, it is possible that clustering exhibits a smaller spatial scale.

\section{Conclusion}

In conclusion, our study shows that malnutrition indicators are spatially heterogeneous across geographic divisions in Bangladesh. Future planning of delivery of nutrition interventions (geographically targeted interventions $v$. random interventions) should consider the spatial clustering of malnutrition indicators observed in the present study.

\section{Acknowledgements}

Acknowledgements: The authors would like to thank The DHS Program for granting permission to use the Bangladesh DHS data. Financial support: This research received no specific grant from any funding agency in the public, commercial or not-for-profit sectors. Conflict of interest: None. Authorship: M.T.H. designed the study, formulated the research question, conducted the statistical analysis, interpreted the findings and wrote the first draft; A.A.M. and G.M.W. contributed to the interpretation, writing and critical revision; R.J.S.M. designed the study, interpreted the findings, and contributed to writing and critical revision. Etbics of human subject participation: This study used publicly available secondary Bangladesh DHS data sets (1999-2000, 2004, 2007 and 2011). Ethical approval was not required.

\section{Supplementary material}

To view supplementary material for this article, please visit https://doi.org/10.1017/S136898001700341X

\section{References}

1. Lim SS, Vos T, Flaxman AD et al. (2012) A comparative risk assessment of burden of disease and injury attributable to 67 risk factors and risk factor clusters in 21 regions, 1990-2010: a systematic analysis for the Global Burden of Disease Study 2010. Lancet 380, 2224-2260.

2. Black RE, Victora CG, Walker SP et al. (2013) Maternal and child undernutrition and overweight in low-income and middle-income countries. Lancet 382, 427-451.

3. Pelletier DL \& Frongillo EA (2003) Changes in child survival are strongly associated with changes in malnutrition in developing countries. J Nutr 133, 107-119.

4. International Food Policy Research Institute (2015) Global Nutrition Report 2015: Actions and Accountability to Advance Nutrition and Sustainable Development. Washington, DC: IFPRI.

5. Frongillo EA Jr, de Onis M \& Hanson KM (1997) Socioeconomic and demographic factors are associated with worldwide patterns of stunting and wasting of children. J Nutr 127, 2302-2309.

6. Smith LC \& Haddad L (2000) Explaining Child Malnutrition in Developing Countries: A Cross-Country Analysis. Washington, DC: IFPRI.

7. United Nations Administratve Committee on Coordination/ Subcommittee on Nutrition (1992) Second Report on the World Nutrition Situation. vol. I: Global and Regional Results. Geneva: ACC/SCN.

8. United Nations Administrative Committee on Coordination/ Subcommittee on Nutrition (1993) Second Report on the World Nutrition Situation. vol. II: Country Trends Methods and Statistics. Geneva: ACC/SCN.

9. Corsi DJ, Chow CK, Lear SA et al. (2011) Shared environments: a multilevel analysis of community context and child nutritional status in Bangladesh. Public Health Nutr 14, 951-959.

10. Griffiths P, Madise N, Whitworth A et al. (2004) A tale of two continents: a multilevel comparison of the determinants of child nutritional status from selected African and Indian regions. Health Place 10, 183-199.

11. Gebreyesus SH, Mariam DH, Woldehanna T et al. (2016) Local spatial clustering of stunting and wasting among children under the age of 5 years: implications for intervention strategies. Public Health Nutr 19, 1417-1427.

12. Michimi A \& Wimberly MC (2010) Spatial patterns of obesity and associated risk factors in the conterminous US. $A m J$ Prev Med 39, e1-e12.

13. Pouliou T \& Elliott SJ (2009) An exploratory spatial analysis of overweight and obesity in Canada. Prev Med 48, 362-367.

14. Tu W, Tedders S \& Tian J (2012) An exploratory spatial data analysis of low birth weight prevalence in Georgia. Appl Geogr 32, 195-207.

15. Morris SS (2001) Targeting urban malnutrition: a multi-city analysis of the spatial distribution of childhood nutritional status. Food Policy 26, 49-64.

16. Fenn B, Morris SS \& Frost C (2004) Do childhood growth indicators in developing countries cluster? Implications for intervention strategies. Public Health Nutr 7, 829-834.

17. Muiruri J, Hulcome P, Schumacher B et al. (2012) WFP Bangladesh Nutrition Strategy 2012-2016. Dhaka: World Food Programme.

18. Hasan MT, Soares Magalhaes RJ, Williams GM et al. (2015) Forecasting the progress towards the target of Millennium 
Development Goal 1C in children under 5 years of age in Bangladesh. Public Health Nutr 18, 1728-1736.

19. Saha KK, Billah M, Menon P et al. (2015) Bangladesh National Nutrition Services: Assessment of Implementation Status. Washington, DC: World Bank.

20. National Institute of Population Research and Training, Mitra and Associates, \& ICF International (2013) Bangladesh Demographic and Health Survey 2011. Dhaka and Calverton, MD: NIPORT, Mitra and Associates, and Macro International.

21. National Institute of Population Research and Training, Mitra and Associates, \& ICF International (2009) Bangladesh Demographic and Health Survey 2007. Dhaka and Calverton, MD: NIPORT, Mitra and Associates, and Macro International.

22. World Health Organization (1995) Physical Status: The Use and Interpretation of Anthropometry. Report of a WHO Expert Committee. WHO Technical Report Series no. 854. Geneva: WHO.

23. WHO Multicentre Growth Reference Study Group (2006) WHO Child Growth Standards: Length/Height-for-Age, Weight-for-Age, Weight-for-Length, Weight-for-Height and Body Mass Index-for Age: Methods and Development. Geneva: WHO.

24. De Onis M \& Blössner M (1997) WHO Global Database on Child Growth and Malnutrition. Geneva: WHO.

25. Cressie N (2015) Statistics for Spatial Data. New York: John Wiley \& Sons.

26. Soares Magalhães RJ, Clements AC et al. (2011) The applications of model-based geostatistics in helminth epidemiology and control. Adv Parasitol 74, 267-296.

27. Soares Magalhães RJ \& Clements AC (2011) Spatial heterogeneity of haemoglobin concentration in preschool-age children in sub-Saharan Africa. Bull World Health Organ 89, 459-468.

28. Ribeiro PJ Jr \& Diggle PJ (2001) A package for geostatistical analysis. R-News 1, 8-15.

29. Bogin B (1999) Patterns of Human Growth, 2nd ed. New York: Cambridge University Press.

30. Adekanmbi VT, Kayode GA \& Uthman OA (2013) Individual and contextual factors associated with childhood stunting in Nigeria: a multilevel analysis. Matern Child Nutr 9. 244-259.

31. Ferdousi S \& Dehai W (2014) Economic growth, poverty and inequality trend in Bangladesh. Asian J Soc Sci Human 3, $1-11$.

32. World Health Organization \& Asia Pacific Observatory on Health Systems and Policies (2015) Bangladesh Health
System Review: Health Systems in Transition. Manila: WHO Regional Office for the Western Pacific.

33. Ajao KO, Ojofeitimi EO, Adebayo AA et al. (2010) Influence of family size, household food security status, and child care practices on the nutritional status of under-five children in Ile-Ife, Nigeria. Afr J Reprod Health 14, 123-132.

34. Kavosi E, Rostami ZH, Kavosi Z et al. (2014) Prevalence and determinants of under-nutrition among children under six: a cross-sectional survey in Fars province, Iran. Int $J$ Health Policy Manag 3, 71-76.

35. UNICEF (2013) Improving Child Nutrition: The Achievable Imperative for Global Progress. New York: UNICEF; available at http://www.unicef.org/publications/index_68661.html

36. Akter T, Mukherjee N, Khan ASM et al. (2015) Climate change impact on agriculture and food security of Barisal district. Presented at International Conference on Climate Change in Relation to Water and Environment (I3CWE2015), Dhaka University of Engineering and Technology, Gazipur, Bangladesh, 9-11 April 2015.

37. National Institute of Population Research and Training, Mitra and Associates, \& ORC Macro (2001) Bangladesh Demographic and Health Survey 1999-2000. Dhaka and Calverton, MD: NIPORT, Mitra and Associates, and ORC Macro.

38. Bangladesh Bureau of Statistics (2011) Report of the Household Income and Expenditure Survey 2010. Dhaka: Ministry of Planning, Government of the People's Republic of Bangladesh.

39. Rudolph L (2011) Increasing food security by asset transfer: evidence of a pro-ultra-poor intervention in Bangladesh. Presented at First International Conference on International Relations and Development (ICIRD), Thammasat University, Bangkok, Thailand, 19-20 May 2011.

40. Uthman OA (2009) A multilevel analysis of individual and community effect on chronic childhood malnutrition in rural Nigeria. J Trop Pediatr 55, 109-115.

41. Pongou R, Ezzati M \& Salomon JA (2006) Household and community socioeconomic and environmental determinants of child nutritional status in Cameroon. BMC Public Health 6, 98.

42. Fotso JC \& Kuate-Defo B (2005) Socioeconomic inequalities in early childhood malnutrition and morbidity: modification of the hosuehold-level effects by the community SES. Health Place 11, 205-225.

43. Boco AG (2010) Individual and Community-Level Effects on Child Mortality: An Analysis of 28 Demographic and Health Surveys in Sub-Saharan Africa. DHS Working Paper no. 73. Calverton, MD: ICF Macro. 